\title{
Estruturação geofísica na área da barragem de Jequitaí - Minas Gerais
}

Teixeira, C. D. ${ }^{1}$; Von Huelsen, M. G. ${ }^{1}$

1. Universidade de Brasília - IGD/Observatório Sismológico

Copyright 2016, SBGf - Sociedade Brasileira de Geofísica

Este texto foi preparado para a apresentação no VII Simpósio Brasileiro de Geofísica, Ouro Preto, 25 a 27 de outubro de 2016. Seu conteúdo foi revisado pelo Comite Técnico do VII SimBGf, mas não necessariamente representa a opinião da SBGf ou de seus associados. É proibida a reprodução total ou parcial deste material para propósitos comerciais sem prévia autorização da SBGf.

\section{Resumo}

Atualmente no Brasil, são poucos os estudos de domínio público que analisam de forma detalhada e integrada a subsuperfície em áreas de barragens. Visando a importância desse assunto, objetiva-se um maior detalhamento geofísico e geológico da região onde serão instalados os reservatórios do Projeto Jequitaí, norte de Minas Gerais, da Companhia de Desenvolvimento dos Vales do São Francisco e do Parnaíba (Codevasf), a fim de contribuir com as informações geológicas/geofísicas da área.

A importância em ajudar na definição de grandes feições geológicas crustais em termos de unidades e estruturas físicas associadas, torna a magnetometria um método geofísico muito importante para auxiliar na formação de uma visão mais abrangente do cenário geológico.

Estudos desta natureza durante as etapas prévias da construção de grandes empreendimentos hidroelétricos se faz de suma importância. A compreensão da geologia regional, conjuntamente com a interpretação dos dados geofísicos e de sismologia podem contribuir para a compreensão das à estruturas e lineamentos na área da barragem. A estruturação prévia da crosta local será um facilitador na compreensão do mecanismo gerador de sismos podendo vir a ser desencadeados ou naturais.

\section{Introdução}

A geofísica é uma ciência voltada para investigação da crosta terrestre em superfície, utilizando-se de medidas das propriedades físicas da Terra e suas interpretações, assim é possível obter informações sobre as estruturas geofísicas e suas composições em profundidade.

Um dos métodos bastante eficiente nessa investigação é a magnetometria, que apresenta como parâmetro físico a susceptibilidade magnética das rochas; com a informação do campo magnético terrestre induzido nas rochas e em estruturas geológicas, que se sobrepõe ou se contrapõe ao campo principal, é possível investigar as fontes causadoras das anomalias.

Trata-se de um método rápido e eficiente, podendo ser adquirido por terra, ar, satélite ou mar. A análise dos dados obtidos pelas diversas plataformas pode ser utilizada para mapeamento geofísico/geológico, para a avaliação de alvos exploratórios, bem como delimitação de áreas alvos para posterior utilização de outros métodos geofísicos de investigação.

O principal objetivo dessa pesquisa é a determinação de parâmetros regionais de profundidade crustal de fontes magnéticas para modelagem de estruturas. Os dados de aeromagnetometria utilizados correspondem àqueles disponíveis no levantamento da Área 13 do estado de Minas Gerais, cedidos pela Companhia de Desenvolvimento Econômico de Minas Gerais (CODEMIG) (Fig. 1).

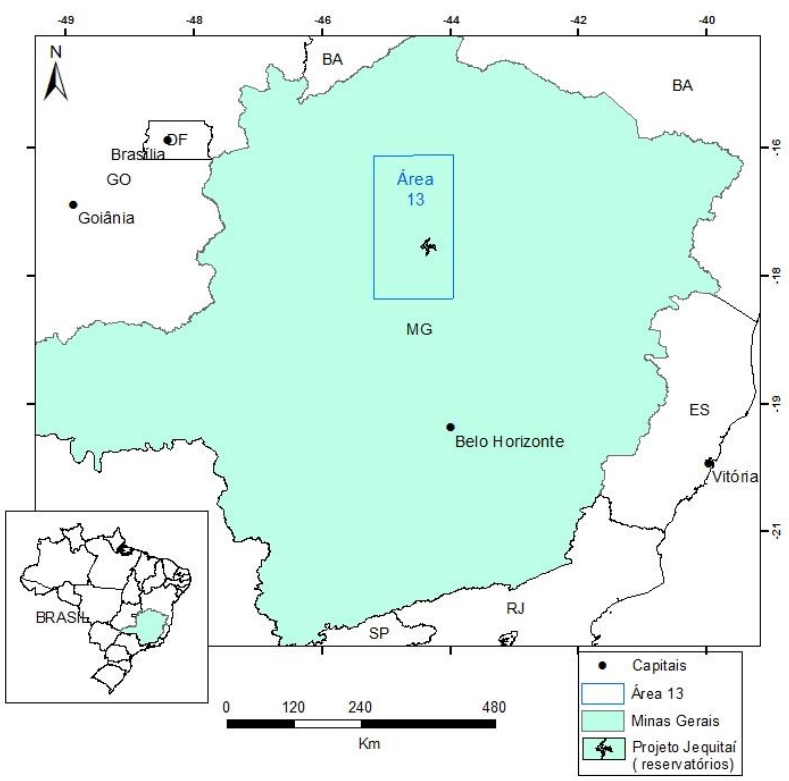

Figura 1 - Localização da área de pesquisa e dos futuros reservatórios do Projeto Jequitaí.

\section{Geologia Regional}

A região localiza-se na porção centro-norte do Estado de Minas Gerais, entre o Rio São Francisco e a Serra do Espinhaço, abrangendo, as serras da Água Fria e das Porteiras e a Serra do Cabral. Segundo Chaves (2010) tais áreas serranas arrasadas representam estruturas anticlinoriais, constituídas em seus núcleos por unidades do Supergrupo Espinhaço, margeado por metassedimentos de unidades mais recentes (Fig. 2).

Em termos geotectônicos, tal região está inserida na margem leste do Cráton São Francisco, próxima ao contato com a Faixa de Dobramentos Araçuaí. Esta região corresponde ao domínio metamórfico externo do orógeno neoproterozóico Araçuaí - Congo Ocidental (Alkmim et al. 2007), onde estão expostos principalmente, os sedimentos dos supergrupos Espinhaço, São Francisco (proterozóicos) e Grupo Areado (fanerozóico).

De acordo com Almeida (1977), o Cráton São Francisco constitui uma área plataformal cujo embasamento se consolidou em tempos pré-brasilianos, servindo assim de antepaís para os dobramentos ocorridos no Evento Brasiliano, responsável pela formação do Órogeno Araçuaí. 
Esses dobramentos ocorridos no Brasiliano ocorreram no estágio sin-colisional, dentro do intervalo compreendido entre 580 e $560 \mathrm{Ma}$ (Pedrosa-Soares et al. 2001, 2007) iniciando-se pelo norte e avançando progressivamente para sul, a colisão das margens opostas da bacia promoveria a propagação de frentes de empurrão para as zonas cratônicas, bem como o soerguimento da cadeia montanhosa (Alkmim et al. 2006, 2007).

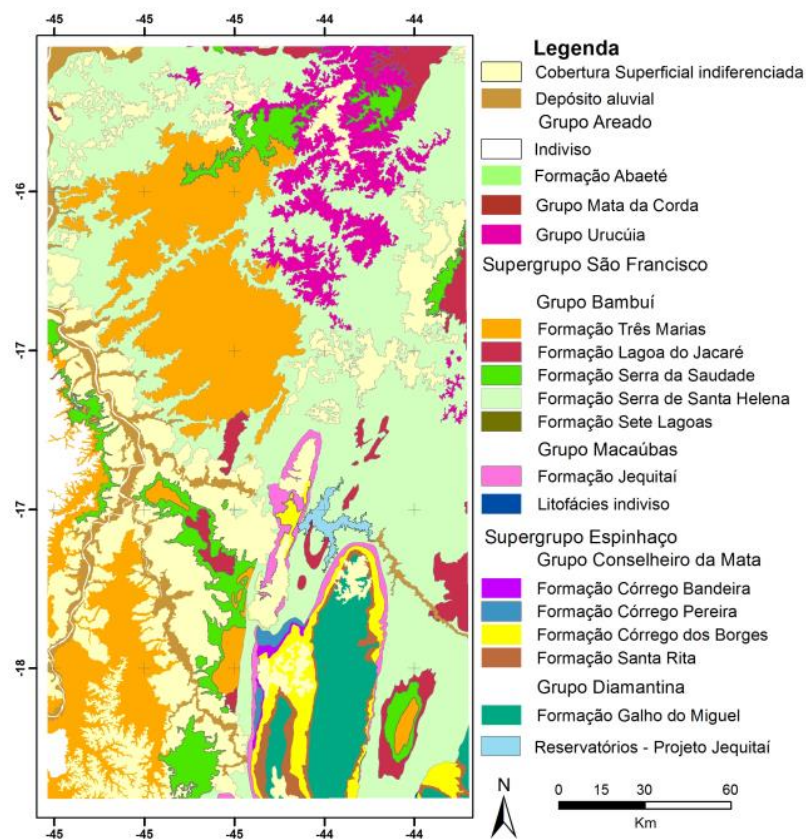

Figura 2 - Mapa geológico (modificado de CPRM, 2014).

\section{Metodologia}

Para estimar a profundidade de fontes das anomalias magnéticas foi utilizado como a principal ferramenta nesse trabalho, o método de deconvolução de Euler, além do espectro de potência do Campo Magnético Anômalo (Figura 3). O Euler consiste em uma análise que elimina a ambiguidade dos dados de campos potenciais magnéticos através da escolha de uma geometria definida anteriormente (Thompson, 1982; Reid et al., 1990). Para isso foi utilizado a plataforma de software Oasis montaj da Geosoft ${ }^{T M}$.

A profundidade aparente para a fonte magnética é derivada a partir da equação homogênea de Euler (1). Esta equação relaciona o campo magnético e as suas componentes para a localização da fonte de uma anomalia:

$$
(\mathrm{x}-\mathrm{x} 0) \frac{\partial}{\partial \mathrm{x}} \mathrm{T}+(\mathrm{y}-\mathrm{y} 0) \frac{\partial}{\partial y} \mathrm{~T}+(\mathrm{z}-\mathrm{z} 0) \frac{\partial}{\partial z} \mathrm{~T}=-\eta \mathrm{T} \text { (1) }
$$

onde ( $x 0$, y0 e z0) é a posição da fonte magnética, $T$ é campo total e $\eta$ corresponde ao índice estrutural, sendo uma medida da taxa de decaimento da anomalia magnética com a distância entre a fonte e 0 ponto de medida, i.e., um indicador da forma geométrica da fonte anômala (por exemplo, $\eta=0$ para um contato, $\eta=1$ para um dique vertical ou uma soleira, $\eta=2$ para um cilindro horizontal ou vertical e $\eta=3$ para uma esfera ou um dipolo).

Foi obtido um mapa de estruturas magnéticas com base nos produtos do Campo Magnético Anômalo (CMA), da Inclinação do Sinal Analítico (ISA), da Amplitude do Sinal Analítico (ASA), do Gradiente Horizontal Total (AGHT) da derivada vertical e suas combinações (Figura 3).

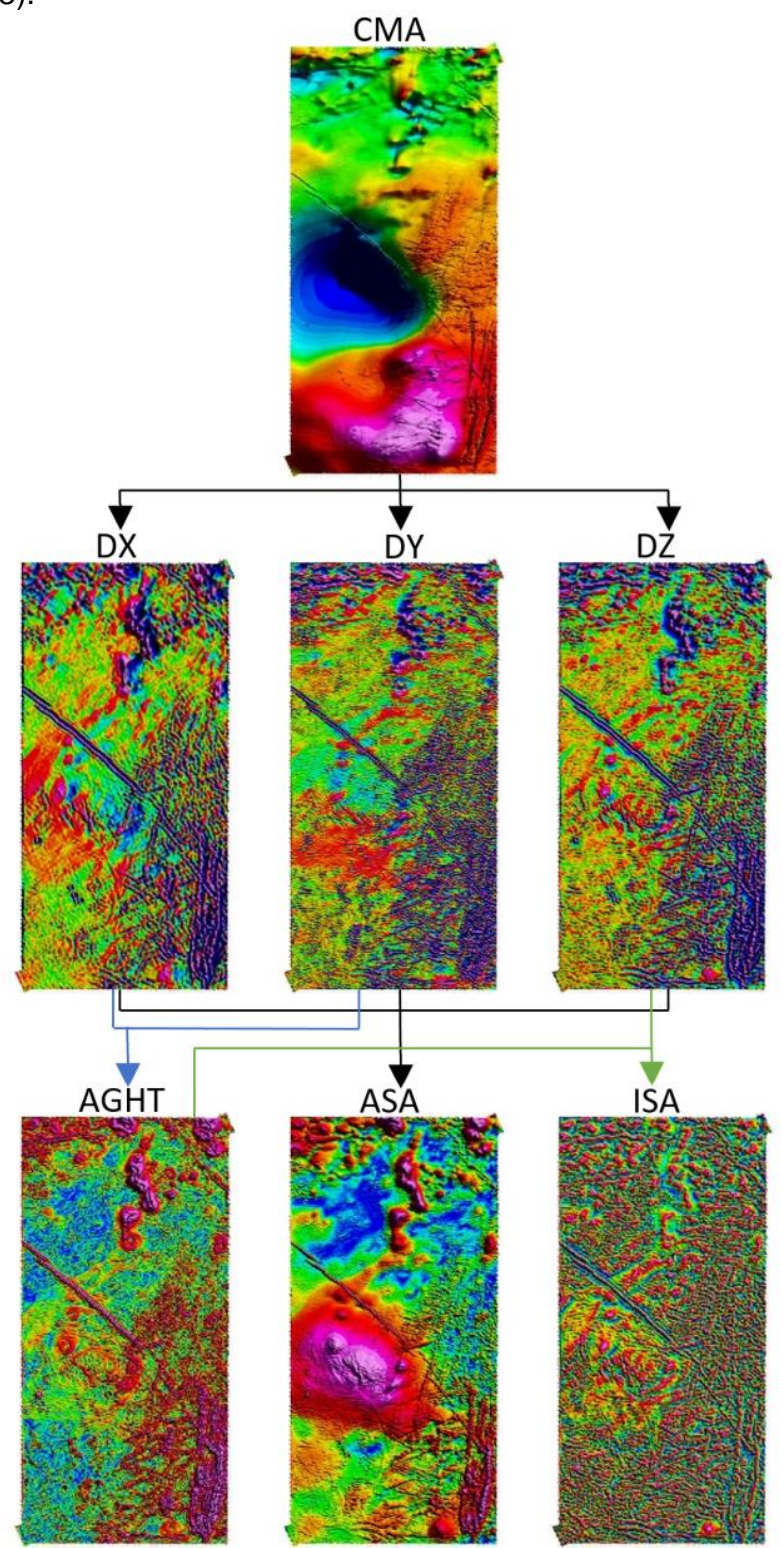

Figura 3 - Fluxograma de processamento dos dados de magnetometria. CMA: campo magnético anômalo; DX: derivada horizontal em X; DY: derivada horizontal em Y; DZ: derivada vertical; AGHT: amplitude do gradiente horizontal total; ASA: amplitude do sinal analítico; ISA: inclinação do sinal analítico.

\section{Resultados}

Com base nos produtos magnéticos (Figura 3) realizou-se a extração de lineamentos magnéticos (análise qualitativa). Esses lineamentos consistem em feições lineares magnéticas, sendo que estas feições 
podem representar diques, falhas geológicas ou contato entre diferentes litotipos (Figura 4).

Uma grande anomalia magnética de formato arredondado, no centro-oeste da área, cercada de várias outras anomalias menores apresentam os mais altos valores de amplitude do sinal analítico dentro da área de trabalho. Apesar disso, esta anomalia não é evidenciada na superfície em termos de geologia pois ela ocorre sob o domínio de rochas das Formações Três Marias e Serra da Saudade, basicamente siltitos, folhelhos e arcósio, o que não justifica a intensidade do sinal.

A porção inferior do mapa, área sudoeste, apresenta várias anomalias alongadas, e uma estruturação com tendência de direcionamento NS. Essa região ocorre sob rochas da Formação Serra de Santa Helena, composta essencialmente por metassiltitos e metargilitos não apresentando também equivalência das altas anomalias magnéticas.

A porção mais ao norte consiste de uma região de baixa amplitude do sinal analítico com ocorrência de corpos menores de mais alta amplitude, apresentando pouca estruturação (Figura 4).

\section{Amplitude de Sinal Analítico}

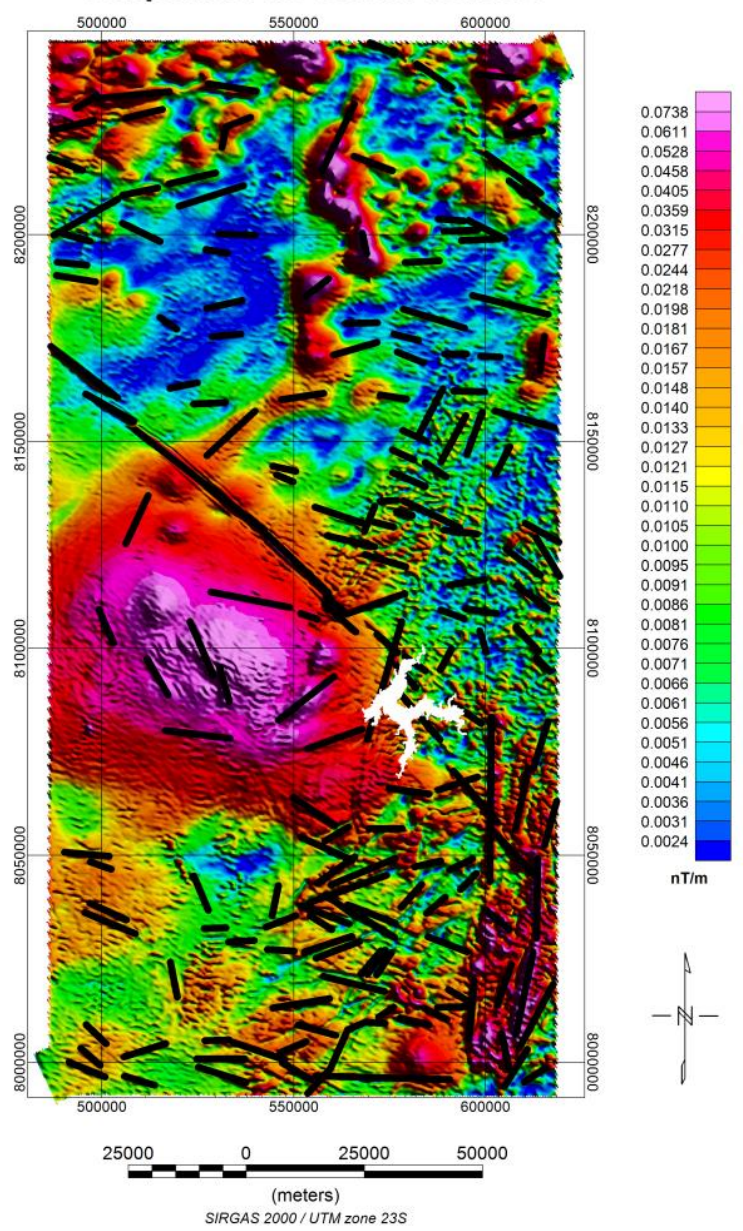

Figura 4 - Mapa de lineamentos magnéticos sobre mapa da amplitude do sinal analítico e reservatórios do Projeto Jequitaí (em branco).
Através da análise do espectro radial de potência (Spector \& Grant, 1970), pode-se inferir que as fontes anômalas mais profundas apresentaram um número de onda menor do que $0,05 \mathrm{~km}^{-1}$, chegando a profundidade de $25 \mathrm{~km}$. Já as fontes intermediárias de $6 \mathrm{~km}$ e fontes rasas de aproximadamente $1,5 \mathrm{~km}$ de profundidade, chegaram a apresentar número de onda da entre 0,3 a $0,75 \mathrm{~km}^{-1}$. A frequência de Nyquist, onde a razão sinal ruído tende a chegar a valores muito baixos ocorre a partir de 0,8 $\mathrm{km}^{-1}$ (Figura 5).

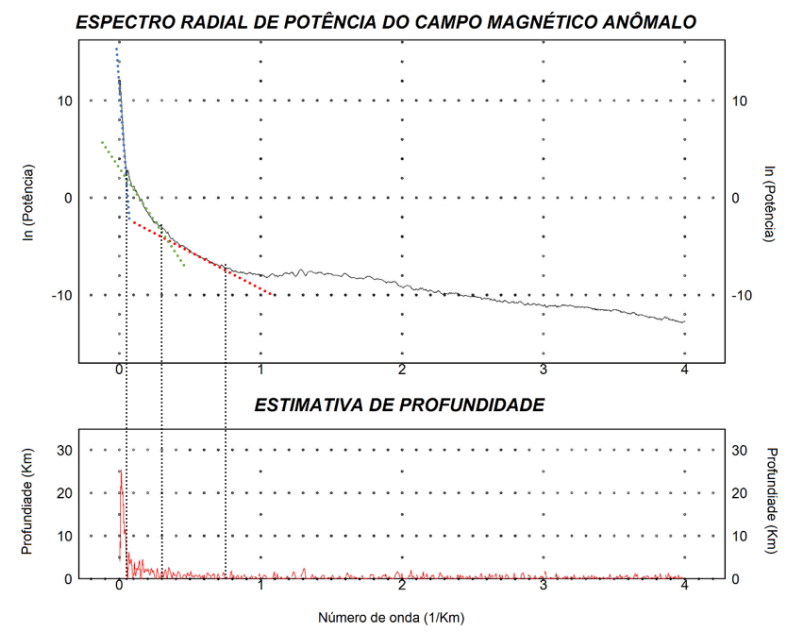

Figura 5 - Espectro radial de potência e estimativa de profundidade das anomalias magnéticas, gerados a partir do mapa do campo magnético anômalo.

As profundidades obtidas pela deconvolução de Euler mostram que a grande anomalia possui maior profundidade comparada com 0 restante da área. Utilizou-se o Euler de índices 0 e 3. O Euler de índice zero mostra um contato raso com profundidade variando de alguns metros no centro da anomalia a $18 \mathrm{~km}$ nas bordas norte e sul da mesma (Figura 6). O Euler de índice 3 (Figura 7) mostra a divisão desta anomalia em dois corpos anômalos, sendo um a sudeste mais raso (profundidade $\sim 30 \mathrm{~km}$ ) e outro adjacente a este (a noroeste) mais profundo e que atinge aproximadamente $35 \mathrm{~km}$ de profundidade (Figura 7).

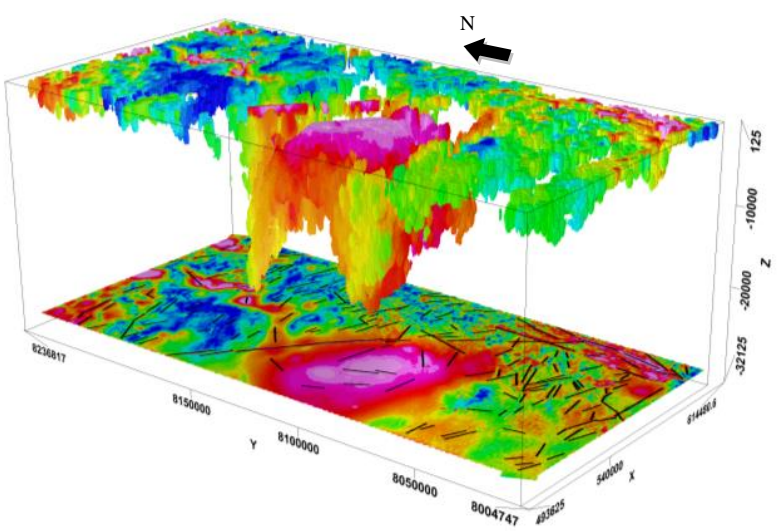

Figura 6 - Resultado em 3D obtido pelo Euler de índice 0 sobre a imagem do ASA e lineamentos magnéticos. 


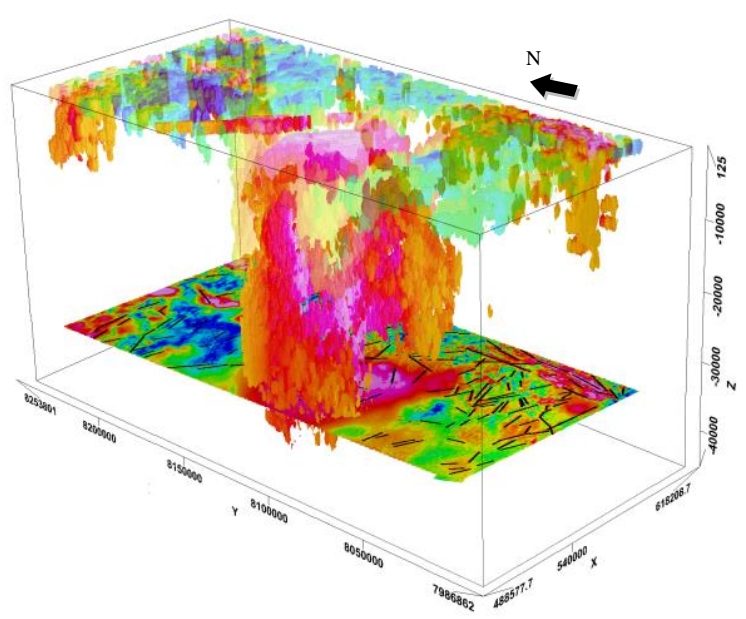

Figura 7: Resultado em 3D obtido pelo Euler de índice 0 (com transparência) e 3 sobre a imagem do ASA.

\section{Discussão}

A aplicação do método de deconvolução de Euler usando os dados do levantamento aeromagnético permitiu uma estimativa da profundidade na região dos futuros reservatórios do Projeto Jequitaí. A análise qualitativa dos lineamentos magnéticos também vem auxiliando em uma melhor estruturação da crosta, estudo esse, que está sendo desenvolvido para gerar um modelo geológico da região.

Se considerarmos a grande anomalia, alongado na direção NW-SE, existente na região, observa-se uma diferenciação em profundidade na parte noroeste (mais profunda) e na parte sudeste (mais rasa), onde no resultado para a deconvolução de Euler de índice 3, apresentou uma maior profundidade que é condizente com o espectro radial de potência (Figura 5). Teixeira et al. (1993) sugeriram a existência de um depocentro sobre essa anomalia, controlado por uma falha normal de grande rejeito de direção E-W.

Os lineamentos a sudeste apresentam direção preferencial NS, com altos valores magnéticos e profundidades rasas visto a partir da deconvolução de Euler (índice 0).

Essa maior profundidade na porção noroeste, observando-se o Euler de índice 0, também ocorre no lineamento principal de direção NW/SE que corta praticamente toda a área e exibe altos valores magnéticos. É possível observar um truncamento deste lineamento com um outro na porção mais central, local esse onde serão construídos os reservatórios.

Essa pesquisa segue, com o propósito de uma melhor compreensão dessas estruturas, caracterização de domínios geofísicos/geológicos e o monitoramento sismológico da região.

\section{Agradecimentos}

Agradecemos à Companhia de Desenvolvimento Econômico de Minas Gerais (CODEMIG) pela liberação dos dados do Levantamento Aerogeofísico e ao Centro de Apoio Desenvolvimento Tecnológico da Universidade de Brasília (CDT/UnB) pela concessão de bolsa a primeira autora e ao Observatório Sismológico pelo apoio à pesquisa.

\section{Referências}

Alkmim F.F., Chemale Jr., F., Endo, I.. 1996. A deformação das coberturas proterozóicas do Cráton do São Francisco. Revista da Escola de Minas, Ouro Preto, v. 48, n.1, p. $14-31$

Alkmim, F.F., Pedrosa-Soares, A.C., Noce, C.M. \& Cruz, S.C.P. 2007. Sobre a Evolução Tectônica do Orógeno Araçuaí-Congo Ocidental. Geonomos, 15.

Almeida, F.F.M. 1977. O Cráton do São Francisco. Revista Brasileira de Geociências, 7: 349-364.

Chaves M.L.S.C., Guimarães J.T., Andrade K.W. $2010 \mathrm{~b}$. Litofácies glaciomarinhas na Formação Jequitaí (MG) e suas implicações na distribuição regional de diamantes. Revista Brasileira de Geociências, 40: 516-526.

Pedrosa-Soares A.C., Noce, C.M., Wiedmann C.M., Pinto C.P. 2001. The Araçuaí-West Congo Orogen in Brazil: an overview of a confined orogen formed during Gondwanaland assembly. Precambrian Research, 110: 307-323.

Pedrosa-Soares, A. C., Noce, C. M., Alkmim, F. F., Silva, L. C., Babinski, M., Copdani, U., Castañeda, C. 2007. Orógeno Araçuaí: Síntese de Conhecimento 30 Anos após Almeida 1977. Geonomos 15(1):1-16.

Reid, A. B; Allsop, J. M; Granser, H; Millett, A. J; Somerton, I. W. 1990. Magnetic interpretation in three dimensions using Euler deconvolution. Geophysics. 55:80-91.

Spector A. \& Grant F. S. 1970. Statistical models for interpreting aeromagnetic data. Geophysics, 35:293-302.

Teixeira L.B., Martins M., Braun O.P.G. 1993. Evolução geológica da Bacia do São Francisco com base em sísmica de reflexão e métodos potenciais. In: SBG, Simp. Craton São Francisco, 2, Salvador, Atas, 179-181.

Thompson, D. T. 1982. Euldph: A new technique for making computer assisted depth estimates from magnetic data. Geophysics, 47: 31-37. 